Research Article

\title{
Is there any differences in post-operative course among the three main types of periampullary tumour?
}

\author{
Mohamed Rabie Saad ${ }^{1,2}$, Ho-Seong Han ${ }^{2 *}$, Yoo-Seok Yoon ${ }^{2}$ and Jai Young Cho ${ }^{2}$ \\ ${ }^{1}$ Department of Surgery, Faculty of Medicine, Aswan University Hospital, Aswan, Egypt \\ ${ }^{2}$ Department of Surgery, Seoul National University Bundang Hospital, Seoul National University College of Medicine, Seoul, Korea
}

\begin{tabular}{l} 
A R T I C L E I N F O \\
\hline Article history: \\
Received: 17 April, 2019 \\
Accepted: 30 April, 2019 \\
Published: 20 May, 2019 \\
Keywords: \\
Post-operative complication \\
pancreatic head cance \\
distal CBD cancer \\
ampulla of vater cancer \\
post-operative course of periampullary \\
tumour
\end{tabular}

\begin{abstract}
A B S T R A C T
Background and objectives: There have been many reports of pancreaticoduodenectomy performed for the surgical treatment of periampullary cancer. However, any differences in the perioperative courses of different types of periampullary tumour are unclear. In this study, we evaluated the differences in morbidity among the three main types of periampullary tumour.

Methods: Prospectively collected data from patients who underwent pancreaticoduodenectomy for periampullary tumour between 2004 to 2018 were reviewed. The patients were divided into three groups: those with pancreatic head cancer, ampulla of Vater (AOV) cancer, or distal common bile duct (CBD) cancer.

Results: Among the 645 patients who underwent pancreaticoduodenectomy, 298 (46.2\%) were diagnosed with pancreatic head cancer, $172(26.7 \%)$ with AOV cancer, and $175(27.1 \%)$ with distal CBD cancer. The group with distal CBD cancer had the highest mean age $(68.45 \pm 9.2$ years; $p=0.002)$ and the highest total bilirubin level $(8.72 \pm 0.6) \mathrm{mg} / \mathrm{dl}$ among the three groups. The group with pancreatic head cancer had the highest rate of firm pancreatic texture $(71.7 \%)$ and the greatest duct diameter $(4.64 \pm 0.2 \mathrm{~mm})$ among the three groups. Pancreatic fistula and pulmonary complications were more frequent in the groups with AOV cancer and distal CBD cancer. Post-operative haemorrhage occurred at a higher rate in the group with distal CBD cancer (12\%). The hospital stay was longer in the group with distal CBD cancer (27.30 \pm 1.3 days). Conclusion: Among the three main types of periampullary tumour, the group with distal CBD cancer had the highest complication rate and the longest hospital stay.
\end{abstract}

\section{Introduction}

Periampullary tumours include pancreatic head cancer, distal common bile duct (CBD) cancer, carcinoma arising from the ampulla of Vater (AOV), and duodenal carcinoma [1]. Although the pathology and survival outcome of each type of tumour differ, their surgical management is the same. Pancreaticoduodenectomy is the only curative treatment for these periampullary tumours [2]. Improvements in surgical instruments, surgical techniques, and perioperative care have led to improvements in outcome and reduced morbidity and mortality after pancreaticoduodenectomy [3]. However, pancreaticoduodenectomy is still one of the most difficult surgical operations and is accompanied by high morbidity and mortality [4]. The common complications of pancreaticoduodenectomy include pancreatic fistula, post-operative haemorrhage, delayed gastric emptying, and generalized complications such as atelectasis, pneumonia, and cardiac complications. Clavien proposed a classification system for surgical complications, graded according to the need for therapeutic treatment [5]. A definition of pancreatic fistula has also been proposed by the International Study Group of Pancreatic Surgery (ISGPS) [6].

It is presumed that all of these complications occur after all types of periampullary tumour. However, the incidence of specific complications may vary among the three types. When developing a treatment plan, it would be useful to know whether there is any difference in the likelihood 
of developing specific complications according to tumour type or in the severity of complications for each tumour type. Therefore, in this study we clarify the differences in morbidity among the different types of periampullary tumour.

\section{Materials and Methods \\ Study design}

Patients who underwent pancreaticoduodenectomy for periampullary tumour in the Department of Surgery, Seoul National University Bundang Hospital, Seoul, Korea, between April 2004 and November 2018 were included in this study. Prospectively collected data on the patients' demographic characteristics, preoperative laboratory and imaging findings, operative and pathological results, post-operative complications, and follow-up were used in the evaluation, after approval was obtained from the Institutional Review Board of Seoul National University Bundang Hospital. Because of the paucity of duodenal cancers and other rare pathologies, these tumours were excluded from the study. The patients were divided into three groups: those with pancreatic head cancer, AOV cancer, or distal CBD cancer.

\section{Preoperative assessment}

The preoperative evaluation protocol included a basic laboratory evaluation of tumour markers, past history of previous abdominal surgery, medical history of chronic diseases, radiological evaluation including triphasic computed tomography (CT) of the abdomen or magnetic resonance imaging (MRI), positron emission tomography (PET) scan, and preoperative cardiac and pulmonary function tests.

\section{Operative techniques}

The surgical treatment for periampullary tumour was either classical pancreaticoduodenectomy (PD) or pylorus-preserving pancreaticoduodenectomy (PPPD) [7, 8]. The commonest type of surgery was PPPD. If the duodenum was involved, especially in patients with pancreatic head cancer, or the blood supply to the duodenum after resection was insufficient, classical PD was performed. The regional lymph nodes and all the adipose tissue around the hepatoduodenal ligament were removed. The reconstruction was performed with ductto-mucosa-type pancreaticojejunostomy using a silastic internal stent. Hepaticojejunostomy was performed with an interrupted monofilament suture, and finally a duodenojejunostomy was performed in patients undergoing PPPD and gastrojejunostomy in those undergoing classical PD. The drains were inserted near the hepaticojejunostomy and pancreaticojejunostomy.

\section{Post-operative assessment}

The post-operative course was closely monitored, and the daily amount of drain output was measured. Abdominal CT was performed routinely on post-operative day 5 to detect early morbidities, such as anastomotic leakage or intra-abdominal accumulation of fluid. Pancreatic fistula has been defined by ISGPS [6]. The complications were graded according to the Clavien-Dindo classification. Grade I involved a deviation from the normal post-operative course that required no intervention and did not lead to life-threatening events. Grade II involved a complication that required pharmacological treatment but no invasive intervention and did not lead to a disability. Grade III involved a complication that required an invasive intervention or readmission to the intensive care unit but did not lead to a disability. Grade IV was any complication that led to a disability and grade $\mathrm{V}$ was any major complication that led to death. Complications of grade III or more were classified as major lifethreatening complications [9].

\section{Statistical analysis}

The data collected were analysed with the SPSS ver. 21 (IBM-SPSS) *. A $\chi^{2}$ test was used to compare the differences in the distribution of frequencies among the different groups. Analysis of variance (ANOVA) was used to test the mean differences in the continuous data that followed a normal distribution, and a post hoc test was performed with Bonferroni's correction.

* IBM_SPSS. Copyright ( ) SPSS Inc., 2011-2012. NY, USA. 2012

\section{Results}

\section{Patient characteristics and preoperative data}

Between April 2004 and November 2018, 645 patients underwent classical PD or PPPD. The indications for surgery included pancreatic head cancer in 298 patients, AOV cancer in 172 patients, and distal CBD cancer in 175 patients. Age was significantly higher in the distal CBD cancer group than in the other groups $(\mathrm{p}=0.002)$. A high rate of patients presented with jaundice, elevated total bilirubin, or frequent biliary drainage procedures in the distal CBD cancer group $(\mathrm{p}<0.001)$ (Table $1)$.

\section{Operative data}

One hundred fifty-one patients (23.4\%) underwent PD and 494 patients (76.6\%) underwent PPPD. A longer operative time $(p=0.049)$ and greater blood loss $(\mathrm{p}<0.001)$ were observed in the pancreatic head cancer group. The pancreatic consistency was firmer $(\mathrm{p}<0.001)$ and the pancreatic duct size wider $(\mathrm{p}<0.001)$ in pancreatic head cancer group than in the other groups (Table 2).

\section{Post-operative data}

There were no differences among the groups in the incidence of cardiac arrest, stroke, or pneumonia. The occurrence of pancreatic fistula was significantly higher in the AOV cancer and distal CBD cancer groups ( $\mathrm{p}$ $<0.001)$. Post-operative bleeding was more frequent in the distal CBD cancer group $(\mathrm{p}<0.001)$. The rate of delayed gastric emptying was significantly higher in the AOV cancer and distal CBD cancer groups ( $\mathrm{p}$ $=0.029)$. Higher incidences of atelectasis and pleural effusion were observed in the AOV cancer and distal CBD cancer groups than in the pancreatic head cancer group $(\mathrm{p}<0.001)$. Complications graded according to the Clavien-Dindo classification were significantly higher in the distal CBD cancer group than in the other groups ( $\mathrm{p}<0.001)$. The hospital stay was significantly longer in the distal CBD cancer group than in the other groups (Table 3). 
Table 1: Demographic data of the study patients

\begin{tabular}{|l|l|l|l|l|l|}
\hline & $\begin{array}{l}\text { Group 1 } \\
\text { Pancreatic } \\
(\mathrm{n}=298)\end{array}$ & $\begin{array}{l}\text { Group 2 } \\
\text { AOV } \\
(\mathrm{n}=172)\end{array}$ & $\begin{array}{l}\text { Group 3 } \\
\text { Distal CBD } \\
(\mathrm{n}=175)\end{array}$ & P-value*,** & P1, P2, P3***** \\
\hline Age/years & $65.18 \pm 10.8$ & $65.25 \pm 10.8$ & $68.45 \pm 9.2$ & $=0.002$ & $=0.948,=0.004,=0.001$ \\
\hline Gender (F/M) & $129 / 169$ & $93 / 79$ & $101 / 74$ & $=0.005$ & $=0.024,=0.287,=0.002$ \\
\hline BMI & $22.59 \pm 2.7$ & $23.96 \pm 2.7$ & $23.58 \pm 3.2$ & $<0.001$ & $<0.001,=0.217,<0.001$ \\
\hline DM \% & $130(43.6 \%)$ & $40(23.3 \%)$ & $46(26.3 \%)$ & $<0.001$ & $<0.001,=0.298,<0.001$ \\
\hline Heart Disease \% & $22(7.4 \%)$ & $15(8.7 \%)$ & $18(10.3 \%)$ & $=0.274$ & \\
\hline Jaundice \% & $148(49.7 \%)$ & $78(45.3 \%)$ & $114(65.1 \%)$ & $<0.001$ & $=0.210,<0.001,=0.001$ \\
\hline Biliary Drainage \% & $166(55.7 \%)$ & $108(62.8 \%)$ & $144(82.3 \%)$ & $<0.001$ & $=0.133,<0.001,<0.001$ \\
\hline T. Bilirubin & $6.19 \pm 0.4$ & $5.09 \pm 0.5$ & $8.72 \pm 0.6$ & $<0.001$ & $=0.120,<0.001,<0.001$ \\
\hline CA-19-9 $(\geq 37$ U/ml) \% & $205(72.7 \%)$ & $71(44.7 \%)$ & $99(61.1 \%)$ & $<0.001$ & $<0.001,=0.003,=0.011$ \\
\hline WBCs & $6.50 \pm 0.1$ & $6.65 \pm 0.2$ & $7.12 \pm 0.2$ & $=0.007$, & $=0.439,=0.030,=0.002$ \\
\hline CRP & $1.49 \pm 0.2$ & $1.54 \pm 0.2$ & $2.15 \pm 0.3$ & $=0.096$ & $=0.879,=0.090,=0.039$ \\
\hline
\end{tabular}

*ANOVA was used to compare the mean differences between groups.

** $\chi 2$ test was used to compare proportions between groups.

****Post hoc test with Bonferroni's correction

$\mathrm{P} 1$ value [group 1vs. 2], P2 value [group 2 vs. 3], P3 value [group 1 vs. 3].

BMI, body mass index; DM, diabetes mellitus; WBC, white blood cell;

CRP, C-reactive protein.

Table 2: Operative characteristics

\begin{tabular}{|c|c|c|c|c|c|}
\hline & $\begin{array}{l}\text { Group } 1 \\
\text { Pancreatic } \\
(n=298)\end{array}$ & $\begin{array}{l}\text { Group } 2 \\
\text { AOV } \\
(n=172)\end{array}$ & $\begin{array}{l}\text { Group } 3 \\
\text { Distal CBD } \\
(\mathrm{n}=175)\end{array}$ & P-value**** & $\mathrm{P} 1, \mathrm{P} 2, \mathrm{P} 3 * *, * * *$ \\
\hline \multicolumn{6}{|l|}{ Operation Name } \\
\hline $\mathrm{PD} \%$ & $91(30.5 \%)$ & $23(13.4 \%)$ & $37(21.1 \%)$ & \multirow[t]{2}{*}{$<0.001$} & \multirow[t]{2}{*}{$<0.001,=0.010,=0.041$} \\
\hline PPPD \% & $207(69.5 \%)$ & $149(86.6 \%)$ & $138(78.9 \%)$ & & \\
\hline Operative Time/min & $408.19 \pm 7.1$ & $390.19 \pm 7.9$ & $382.95 \pm 8.4$ & $=0.049$ & $=0.102,=0.557,=0.021$ \\
\hline Blood Loss $/ \mathrm{ml}$ & $527.21 \pm 24.6$ & $313.20 \pm 17.6$ & $369.94 \pm 27.7$ & $<0.001$ & $<0.001,=0.150,<0.001$ \\
\hline \multicolumn{6}{|c|}{ Pancreatic Consistency $(\mathrm{n}=533)$} \\
\hline Duct Size/mm & $4.64 \pm 0.2$ & $3.59 \pm 0.1$ & $2.83 \pm 0.1$ & $<0.001$ & $<0.001,=0.004,<0.001$ \\
\hline Soft $\%$ & $70(28.3 \%)$ & $104(74.3 \%)$ & $108(74 \%)$ & \multirow{2}{*}{$<0.001$} & \multirow[t]{2}{*}{$<0.001,=0.530,<0.001$} \\
\hline Firm $\%$ & $177(71.7 \%)$ & $36(25.7 \%)$ & $38(26 \%)$ & & \\
\hline PO Drain Amylase & $312.46 \pm 62.2$ & $1328.83 \pm 277$ & $1029.69 \pm 118.8$ & $<0.001$ & $<0.001,=0.193,<0.001$ \\
\hline
\end{tabular}

*ANOVA was used to compare the mean differences between groups.

*** $\chi 2$ test was used to compare proportions between groups.

***Post hoc test with Bonferroni's correction

P1 value [group 1vs. 2], P2 value [group 2 vs. 3], P3 value [group 1 vs. 3]. 
Table 3: Post-operative complications in the study groups

\begin{tabular}{|c|c|c|c|c|c|}
\hline & $\begin{array}{l}\text { Group } 1 \\
\text { Pancreatic } \\
(\mathrm{n}=298)\end{array}$ & $\begin{array}{l}\text { Group } 2 \\
\text { AOV } \\
(\mathrm{n}=172)\end{array}$ & $\begin{array}{l}\text { Group } 3 \\
\text { Distal CBD } \\
(\mathrm{n}=175)\end{array}$ & P-value*,** & $\mathrm{P} 1, \mathrm{P} 2, \mathrm{P} 3 * *, * * *$ \\
\hline $\mathrm{CDC} \%$ & & & & $<0.001$ & $<0.001,=0.035,<0.001$ \\
\hline None & $105(35.2 \%)$ & $28(16.3 \%)$ & $22(12.6 \%)$ & & \\
\hline I & $76(25.5 \%)$ & $63(36.6 \%)$ & $49(28 \%)$ & & \\
\hline II & $42(14.1 \%)$ & $30(17.4 \%)$ & $37(21.1 \%)$ & & \\
\hline$\geq \mathrm{III}$ & $75(25.2 \%)$ & $51(29.7 \%)$ & $67(38.3 \%)$ & & \\
\hline PJ Leakage \% & $48(16.1 \%)$ & $88(51.2 \%)$ & $86(49.1 \%)$ & $<0.001$ & $<0.001,=0.458,<0.001$ \\
\hline \multicolumn{6}{|l|}{ PJ Leakage Type \% } \\
\hline A & $24(8.1 \%)$ & $56(31.7 \%)$ & $49(28 \%)$ & & \\
\hline B & $22(7.4 \%)$ & $32(18.6 \%)$ & $36(20.5 \%)$ & $<0.001$ & $<0.001,=0.627,<0.001$ \\
\hline $\mathrm{C}$ & $2(0.7 \%)$ & $0(0 \%)$ & $1(0.6 \%)$ & & \\
\hline PO Bleeding $\%$ & $13(4.4 \%)$ & $3(1.8 \%)$ & $21(12 \%)$ & $<0.001$ & $=0.134,<0.001,=0.002$ \\
\hline Delayed Gast. Emp. \% & $12(4 \%)$ & $17(9.9 \%)$ & $15(8.6 \%)$ & $=0.029$ & $=0.010,=0.400,=0.034$ \\
\hline Biliary Fistula \% & $0(0 \%)$ & $3(1.8 \%)$ & $3(1.7 \%)$ & $=0.042$ & $=0.048,=0.647,=0.023$ \\
\hline Liver Abscess \% & $0(0 \%)$ & $2(1.2 \%)$ & $5(2.9 \%)$ & $=0.015$ & $=0.050,=0.234,=0.007$ \\
\hline Atelectasis \% & $46(15.4 \%)$ & $60(35.3 \%)$ & $58(33.1 \%)$ & $<0.001$ & $<0.001,=0.379,<0.001$ \\
\hline Pleural Effusion $\%$ & $36(12.1 \%)$ & $43(25.1 \%)$ & $43(24.6 \%)$ & $<0.001$ & $<0.001,=0.500,<0.001$ \\
\hline Pneumonia $\%$ & $8(2.7 \%)$ & $2(1.2 \%)$ & $4(2.3 \%)$ & $=0.516$ & \\
\hline \multicolumn{6}{|l|}{$\begin{array}{l}\text { Cardiac Complication } \\
\%\end{array}$} \\
\hline MI & $0(0 \%)$ & $0(0 \%)$ & $2(1.1 \%)$ & $=0.044$ & $=1.000,=0.050,=0.039$ \\
\hline Pulmonary Embolism & $0(0 \%)$ & $2(1.2 \%)$ & $3(1.7 \%)$ & $=0.034$ & $=0.050,=0.292,=0.024$ \\
\hline Arrest & $3(1.0 \%)$ & $1(0.6 \%)$ & $5(2.9 \%)$ & $=0.137$ & \\
\hline Stroke/CVA & $0(0 \%)$ & $1(0.6 \%)$ & $0(0 \%)$ & $=0.820$ & \\
\hline Hospital stay/ds & $23.22 \pm 1.9$ & $22.45 \pm 1.1$ & $27.30 \pm 1.3$ & $=0.005$ & $=0.598,=0.003,=0.005$ \\
\hline
\end{tabular}

*ANOVA was used to compare the mean differences between groups.

** $\chi 2$ test was used to compare proportions between groups.

****Post hoc test with Bonferroni's correction

$\mathrm{P} 1$ value [group 1vs. 2], P2 value [group 2 vs. 3], P3 value [group 1 vs. 3].

CDC, Clavien-Dindo classification: PJ, pancreaticojejunostomy; MI, myocardial infarction.

\section{Discussion}

Pancreaticoduodenectomy is considered one of the most difficult surgeries and is accompanied by a complicated post-operative course. The morbidity rate for this operation remains high, despite improvements in perioperative care, instruments, and the management of anaesthesia. Severe complications can influence the survival of patients, as has been reported previously by our team [9, 10]. Many studies have reported the complications of pancreaticoduodenectomy and their risk factors. However, there has been no report of the differences in the incidence of complications after pancreaticoduodenectomy among the different types of periampullary tumour [11, 12]. Pancreatic fistula is a frequent and important complication of post-pancreaticoduodenectomy, and also leads to multiple other morbidities, such as intra-abdominal abscess, postoperative bleeding, and delayed gastric emptying [13, 14]. The risk factors for pancreatic fistula are reported to be a narrow pancreatic duct, a soft-textured pancreas and the experience of the surgeon. In this study, the pancreatic texture was firmer in the pancreatic head cancer group, which also had a larger pancreatic duct diameter compared with the
AOV cancer and distal CBD cancer groups. Consequently, the incidence of pancreatic fistula was higher in the AOV cancer and distal CBD cancer groups. Although the cause of the high pancreatic fistula rate in these tumours is not understood, it might result from the soft pancreatic texture and narrow diameter of the pancreatic duct in these tumours [1517].

Post-pancreaticoduodenectomy haemorrhage is considered a serious and sometimes fatal complication and is associated with a high mortality rate (up to $30 \%$ ), increased hospital stay, and higher medical costs [18]. The causes of post-operative haemorrhage are reportedly related to pseudoaneurysm and vascular erosion [19]. In the present study, there was a high incidence of post-operative haemorrhage in the group with distal CBD cancer, although the reason is unclear. We assume that the large proportion of elderly patients in this group played a role in the frequent occurrence of post-operative haemorrhage, because it is reported that old age is associated with arterial structural changes, atherosclerosis, and coronary and cerebral artery diseases [20]. Another possible cause was that the high rate of pancreatic fistula in the patients with distal CBD cancer affected the occurrence of post-operative haemorrhage. It should 
be noted that the group of patients with AOV also had a high rate of pancreatic fistula, but their rate of post-operative haemorrhage was not high. Further study is required to understand the discrepancy between post-operative pancreatic fistula and post-operative haemorrhage in this group.

The commonest clinical finding in patients with periampullary tumours is jaundice, and it has been reported that jaundice increases the morbidity rate after pancreaticoduodenectomy. The distal CBD cancer group had the largest proportion of patients presenting with jaundice, and also the highest mean total bilirubin level among the groups [21, 22]. The group with distal CBD cancer also had high white blood cell counts and high levels of C-reactive protein, which may indicate preoperative cholangitis. Cholangitis adversely affects the post-operative course and may lead to systemic inflammation or local inflammation. Local inflammation promotes intra-abdominal infection and weakness of the adjacent vessel wall. Therefore, old age, the high rate of pancreatic fistula, and the increased rate of inflammation in the distal CBD group might explain the high rate of post-operative haemorrhage in this group [23]. Delayed gastric emptying is an early complication of pancreaticoduodenectomy. Although it might not be associated with high mortality, it can affect the patient's post-operative course, quality of life, and post-operative hospital stay [24]. The causes of delayed gastric emptying can be multifactorial. Intra-abdominal accumulation of fluid and pancreatic fistula is thought to play an important role in the incidence of delayed gastric emptying. It is well known that delayed gastric emptying is more frequent after PPPD than after classical PD. In this study, the groups with AOV and distal CBD cancer underwent PPPD more frequently than did the pancreatic head cancer group. The pancreatic fistula rate was also high in the groups with AOV cancer or distal CBD cancer, which might have affected delayed gastric emptying. These conditions might explain why delayed gastric emptying was higher in the patients with AOV cancer or distal CBD cancer [25, 26].

Pleural effusion and atelectasis are common post-operative complications and may be occasionally difficult to distinguish because atelectasis can be accompanied by pleural effusion (compression atelectasis) [27]. Post-operative pleural effusion is a well-known postoperative finding in patients with pancreatic fistula or intra-abdominal infection. In this study, atelectasis and pleural effusion were common in the AOV cancer and distal CBD cancer groups. We presumed that the occurrence of these pulmonary complications was attributable to the high incidence of pancreatic fistula. Old age might also have contributed to the high incidence of atelectasis and pleural effusion in the distal CBD cancer group [28]. Cardiac complications are important post-operative events because they can increase mortality. Age can be a factor affecting the incidence of cardiac complications after surgery, and old age is reported to increase cardiac complications by about 2.6-fold [29]. Cardiac complications, such as myocardial infarction, were higher in the distal CBD cancer group, as was pulmonary embolism. This might be attributable to the high mean age and high rate of pre-existing heart disease in this group [30, 31]. The duration of hospital stay increases hospital costs. The mean hospital stay was significantly longer in the distal CBD group than in the other groups in this study because of the high incidence of morbidity. The limitations of this study were that it was retrospective, and the sample size was insufficiently large. A prospective study with a large cohort will better illustrate the pathophysiological mechanisms of these post-operative complications.
However, this is one of the earliest studies to show the differences in the post-operative course of PD among the three main types of periampullary tumour.

In conclusion, periampullary tumours differ significantly in their perioperative courses after PD, with a higher rate of morbidity, longer hospital stays and higher costs in patients with distal CBD cancer.

\section{Funding}

None

\section{Author Contributions}

Mohamed Rabie Saad: concept of the study, writing the article. Ho-Seong Han: concept of the study, critical review.

Yoo-Seok Yoon, Jai Young Cho: data collection, review of the article.

\section{REFERENCES}

1. Kimura W, Futakawa N, Zhao B (2004) Neoplastic diseases of the papilla of Vater. J Hepatobiliary Pancreat Surg 11: 223-231. [Crossref]

2. Takagi K, Yagi T, Yoshida R, Shinoura S, Umeda Y et al. (2016) Surgical Outcome of Patients Undergoing Pancreaticoduodenectomy: Analysis of a 17-Year Experience at a Single Center. Acta Med Okayama 70: 197-203. [Crossref]

3. Balcom JHT, Rattner DW, Warshaw AL, Chang Y, Fernandez-del Castillo C (2001) Ten-year experience with 733 pancreatic resections: changing indications, older patients, and decreasing length of hospitalization. Arch Surg 136: 391-398. [Crossref]

4. Behrman SW, Rush BT, Dilawari RA (2004) A modern analysis of morbidity after pancreatic resection. Am Surg 70: 675-682. [Crossref]

5. Cameron JL, He J (2015) Two thousand consecutive pancreaticoduodenectomies. J Am Coll Surg 220: 530-536. [Crossref]

6. Bassi C, Marchegiani G, Dervenis C, Sarr M, Abu Hilal M et al. (2017) The 2016 update of the International Study Group (ISGPS) definition and grading of postoperative pancreatic fistula: 11 Years After. Surgery 161: 584-591. [Crossref]

7. Del Chiaro M, Valente R, Arnelo U (2017) Minimally Invasive Pancreaticoduodenectomy for the Treatment of Pancreatic-Head and Periampullary Tumors. JAMA Surg 152: 343. [Crossref]

8. Romano G, Agrusa A, Galia M, Di Buono G, Chianetta D et al. (2015) Whipple's pancreaticoduodenectomy: Surgical technique and perioperative clinical outcomes in a single center. Int J Surg 1: S68S71. [Crossref]

9. Cho JY, Han HS, Yoon YS, Hwang DW, Jung K et al. (2013) Postoperative complications influence prognosis and recurrence patterns in periampullary cancer. World J Surg 37: 2234-2241. [Crossref]

10. Elberm H, Ravikumar R, Sabin C, Abu Hilal M, Aroori S et al. (2015) Outcome after pancreaticoduodenectomy for T3 adenocarcinoma: a multivariable analysis from the UK vascular resection for pancreatic Cancer study group. Eur J Surg Oncol 41: 1500-1507. [Crossref]

11. Feng J, Chen YL, Dong JH, Chen MY, Cai SW et al. (2014) Postpancreaticoduodenectomy hemorrhage: risk factors, managements and outcomes. Hepatobiliary Pancreat Dis Int 13: 513-522. [Crossref] 
12. Nentwich MF, El Gammal AT, Lemcke T, Ghadban T, Bellon E et al. (2015) Salvage completion pancreatectomies as damage control for post-pancreatic surgery complications: a single-center retrospective analysis. World J Surg 39: 1550-1556. [Crossref]

13. Bassi C, Dervenis C, Butturini G, Fingerhut A, Yeo C et al. (2005) Postoperative pancreatic fistula: an international study group (ISGPF) definition. Surgery 138: 8-13. [Crossref]

14. Lai EC, Lau SH, Lau WY (2009) Measures to prevent pancreatic fistula after pancreatoduodenectomy: a comprehensive review. Arch Surg 144: 1074-1080. [Crossref]

15. de Castro SM, Busch OR, van Gulik TM, Obertop H, Gouma DJ (2005) Incidence and management of pancreatic leakage after pancreatoduodenectomy. Br J Surg 92: 1117-1123. [Crossref]

16. Yeo CJ, Cameron JL, Maher MM, Sauter PK, Zahurak ML et al. (1995) A prospective randomized trial of pancreaticogastrostomy versus pancreaticojejunostomy after pancreaticoduodenectomy. Ann surg 222: 580-588. [Crossref]

17. Poon RT, Fan ST, Lo CM, Ng KK, Yuen WK et al. (2007) External drainage of pancreatic duct with a stent to reduce leakage rate of pancreaticojejunostomy after pancreaticoduodenectomy: a prospective randomized trial. Ann surg 246: 425-433. [Crossref]

18. Limongelli P, Khorsandi SE, Pai M, Jackson JE, Tait J et al. (2008) Management of delayed postoperative hemorrhage after pancreaticoduodenectomy: a meta-analysis. Arch Surg 143: 10011007. [Crossref]

19. de Castro SM, Kuhlmann KF, Busch OR, van Delden OM, Lameris JS et al. (2005) Delayed massive hemorrhage after pancreatic and biliary surgery: embolization or surgery? Ann surg 241: 85-91. [Crossref]

20. Lakatta EG (2015) So! What's aging? Is cardiovascular aging a disease? J Mol Cell Cardiol 83: 1-13. [Crossref]

21. Cooper AB, Lillemoe KD (2018) Periampullary Cancer: Clinical Presentation and Diagnostic Strategies. The Pancreas: An Integrated Textbook of Basic Science. Med Surg 1035-1046.

22. Sauvanet A, Boher JM, Paye F, Bachellier P, Sa Cuhna et al. (2015) Severe Jaundice Increases Early Severe Morbidity and Decreases
Long-Term Survival after Pancreaticoduodenectomy for Pancreatic Adenocarcinoma. J Am Coll Surg 221: 380-389. [Crossref]

23. Kitahata Y, Kawai M, Tani M, Hirono S, Okada K et al. (2014) Preoperative cholangitis during biliary drainage increases the incidence of postoperative severe complications after pancreaticoduodenectomy. Am J Surg 208: 1-10. [Crossref]

24. Qu H, Sun GR, Zhou SQ, He QS (2013) Clinical risk factors of delayed gastric emptying in patients after pancreaticoduodenectomy: a systematic review and meta-analysis. Eur J Surg Oncol 39: 213-223. [Crossref]

25. Kawai M, Tani M, Hirono S, Miyazawa M, Shimizu A et al. (2011) Pylorus ring resection reduces delayed gastric emptying in patients undergoing pancreatoduodenectomy: a prospective, randomized, controlled trial of pylorus-resecting versus pylorus-preserving pancreatoduodenectomy. Ann surg 253: 495-501. [Crossref]

26. Yeo CJ, Barry MK, Sauter PK, Sostre S, Lillemoe KD et al. (1993) Erythromycin accelerates gastric emptying after pancreaticoduodenectomy. A prospective, randomized, placebocontrolled trial. Ann surg 218: 229-237. [Crossref]

27. Marik Paul (2010) Pleural Effusions and Atelectasis.

28. Addeo P, Delpero JR, Paye F, Oussoultzoglou E, Fuchshuber PR et al. (2014) Pancreatic fistula after a pancreaticoduodenectomy for ductal adenocarcinoma and its association with morbidity: a multicentre study of the French Surgical Association. $H P B(O x$ ford $)$ 16: 46-55. [Crossref]

29. Casadei R, Ricci C, Lazzarini E, Taffurelli G, D’Ambra M et al. (2014) Pancreatic resection in patients 80 years or older: a meta-analysis and systematic review. Pancreas 43: 1208-1218. [Crossref]

30. Beltrame V, Gruppo M, Pastorelli D, Pedrazzoli S, Merigliano S et al. (2015) Outcome of pancreaticoduodenectomy in octogenarians: single institution's experience and review of the literature. J Visc Surg 152: 279-284. [Crossref]

31. 31. Sebastian G de la Fuente, Kyla M Bennett, Theodore N Pappas, John E Scarborough (2011) Pre and intraoperative variables affecting early outcomes in elderly patients undergoing pancreaticoduodenectomy. $H P B(O x$ ford $)$ 13: 887-892. [Crossref] 